\title{
Monetary Policy Rules Based on Real-Time Data
}

\author{
Athanasios Orphanides* \\ Board of Governors of the Federal Reserve System
}

December 1997

\begin{abstract}
In recent years, simple policy rules have received attention as a means to a more transparent and effective monetary policy. Often, however, the analysis is based on unrealistic assumptions about the timeliness of data availability. This permits rule specifications that are not operational and ignore difficulties associated with data revisions.

This paper examines the magnitude of these informational problems using Taylor's rule as an example. First, I construct a database of current quarter estimates/forecasts of the quantities required by the rule based only on information available in real time. Using this data I reconstruct the policy recommendations which would have been obtained in real time. I demonstrate that the real-time policy recommendations differ considerably from those obtained with the ex post revised data. Within-year revisions in the policy recommendations are also quite large with a standard deviation exceeding that of the quarterly change of the federal funds rate.

Further, I show that estimated policy reaction functions obtained using the ex post revised data can yield misleading descriptions of historical policy. Using Federal Reserve staff forecasts I show that in the 1987-1992 period simple forward-looking specifications describe policy better than comparable Taylor-type specifications, a fact that is largely obscured when the analysis is based on the ex post revised data.
\end{abstract}

KEYWORDS: Monetary policy rules, federal funds rate, Taylor rule, real-time data.

JEL Classification System: E52, E58

Correspondence: Division of Monetary Affairs, Board of Governors of the Federal Reserve System, Washington, D.C. 20551. Tel.: (202) 452-2654, email: aorphanides@frb.gov

* I would like to thank Helen Douvogiannis and Rebecca Zarutskie for their superb assistance with the organization of the data during the summer of 1997 and Kendrew Witt for valuable research assistance. I would also like to thank Charles Calomiris, Dean Croushore, Bill English, David Lindsey, Adrian Pagan, Dick Porter, Brian Sack, and participants at presentations at New York University and a System Committe on Macroeconomics Conference at the Federal Reserve Bank of New York for useful discussions and comments. The opinions expressed are those of the author and do not necessarily reflect views of the Board of Governors of the Federal Reserve System. 


\section{Introduction}

In recent years, simple policy rules have received attention as a means towards a more transparent and effective monetary policy. A series of papers have examined the performance of such rules in theoretical as well as empirical terms. ${ }^{1}$ Such rules typically specify that the monetary authority set its operating instrument as a function of one or two observable variables reflecting inflationary and real activity conditions in the economy.

Often, however, the analysis underlying these policy rules is based on unrealistic assumptions about the timeliness of data availability and ignores difficulties associated with the accuracy of initial data and subsequent revisions. For example, the rule proposed by Taylor (1993), recommends setting the federal funds rate using the current-quarter output gap and inflation based on the output deflator. Taylor's rule has received considerable attention in large part because he demonstrated that the simple rule described the actual behavior of the federal funds rate rather surprisingly well. But as is well known, the actual variables required for implementation of such a rule-potential output, nominal output, and real output - are not known with any accuracy until much later. That is, the rule does not describe a policy that the Federal Reserve could have actually followed.

The primary source of this problem is the reliance on ex post revised data for the analysis. Indeed, standard practice in empirical macroeconomics is to employ ex post revised data for the analysis of historical time series without adequate investigation of the possible consequences of this practice on the results. ${ }^{2}$ However, the measurement of many concepts of interest, for instance of output and its price, is fraught with considerable uncertainties that are resolved only slowly and perhaps never completely. Although this informational problem may not be of significance for some purposes, it is likely to be of great importance

\footnotetext{
${ }^{1}$ See Henderson and McKibbin, 1993; Taylor, 1993; Bernanke and Woodford, 1996; Fair and Howrey, 1996; Levin, 1996; Ball, 1997; Fuhrer, 1997; Clarida and Gertler, 1997; McCallum, 1997; Rotemberg and Woodford, 1997; Svensson, 1997 and the conference volumes edited by Bryant, Hooper and Mann, 1993 and by Lowe, 1997. Clarida, Gali and Gertler, 1997b, provide an extensive survey.

${ }^{2}$ Throughout, I refer to the informational problem as one associated with data "revisions" but this should be interpreted to include redefinitions and rebenchmarks although, strictly speaking, these pose slightly different problems in some respects.
} 
when the investigation concentrates on how policymakers react or how they ought to react to current information for setting policy. But this is exactly the purpose of the study of simple reactive monetary policy rules.

Informational problems can have a significant impact in the analysis of policy rules for several reasons. The first, and perhaps most direct, regards rules based on contemporaneous data. Simply, rules that rely on within-quarter reaction to information about that quarter are not operational. ${ }^{3}$ In principle this problem can be dealt with either by recognizing that the policy maker will have to employ within-quarter forecasts to operationalize the rule or by specifying that policy react to the latest available "current" information where current would refer to the last quarter for which data are available. But in either case, the suggested policy prescribed by the rule will differ from what would obtain if the rule were evaluated using ex post revised data.

A thornier issue concerns the influence of data revisions on the "proper" policy setting suggested by a reactive rule. Retrospectively, the "appropriate" policy setting for a particular quarter may appear different with subsequent renditions of the data necessary to evaluate the rule for that quarter. Through a distorted glass, the interpretation of historical episodes may change. Policy that was in accordance with a fixed rule at the time the policy was set may appear instead to have been excessively easy or tight and vice versa.

This issue is also of importance in the context of econometric model-based evaluations of alternative policy rules. Standard current practice in such evaluations is to specify the policy instrument in terms of the variables it is reacting to as if these variables were known to the policymaker with certainty and were not subject to revisions. That is, evaluation of alternative policy rules is conditioned on the implicit assumption that none of the alternative rules examined is subject to the informational problem. However, since the influence of data revisions on the suggested policy setting varies from one policy rule to another, rules that appear best in the absence of informational problems could be dominated by alternatives once the informational problem is properly treated. For instance, if a rule specifies that

\footnotetext{
${ }^{3}$ This problem was pointed out by McCallum (1993a,b)
} 
the federal funds rate react to the previous quarter's output, proper evaluation of the rule ought to account for the fact that the estimate of the previous quarter's output available to a policymaker at the time policy must be set is subject to error-the error associated with subsequent revisions in the measurement of the previous quarter's output. Likewise, evaluation of forward-looking rules that specify a reaction to forecasts of macroeconomic variables ought to account for the fact that in real time such forecasts will be based on preliminary data that are subject to revision. Forecasts based on the revised information would consequently differ from their real-time counterparts.

Reliance on ex post revised data can also prove misleading in efforts to identify the historical pattern of policy by estimating policy reaction functions. The noise introduced by data revisions might bias the estimated response to some variables and obscure differences in reactions to alternative sets of variables. Even with a correctly specified reaction function, ensuring that the estimated parameters would be free of such bias might be difficult. As well, residuals obtained from reaction functions fitted with ex post revised data will be difficult to interpret as monetary policy surprises. Even with the appropriate reaction function in place, the estimated residuals would reflect, in part, the artificial contribution of data revisions.

This paper examines the magnitude of the informational problem using Taylor's rule as an illustration. To this end, I construct a database of current quarter estimates/forecasts of the quantities required by the rule based only on information available in real time. Using information which is now publicly available from the Federal Reserve for the original sample covered by Taylor, I use estimates of output, potential output and inflation, made by the Federal Reserve staff in real-time, to reconstruct the policy recommendations that would have been obtained based on the rule. I show that the real time policy recommendations differ widely from those obtained with the revised published data employed later on. A decomposition of the revision of the rule quarter-by-quarter reveals substantial variation in the rule recommendations even one year after the quarter to which the original policy setting would apply. Revisions regarding both ingredients in the rule, inflation and output, 
contribute to this variance.

Examination of linear policy reaction functions based on the real-time data uncovers alternative rules that appear to provide a more accurate depiction of the actual federal funds rate than Taylor's original specification. Using the real-time Federal Reserve staff forecasts, I show that estimated rules that respond to the forecasts of inflation and the output gap appear to provide a better description of policy from 1987 to 1992 than rules specifying a response to the lagged or within-quarter counterparts of these variables. I also show that this fact is largely obscured when ex post revised data is used for such an evaluation.

The remainder of the paper is organized into four sections. Section 2 reconstructs Taylor's rule as it originally appeared, and compares the recommendations for the federal funds rate that he originally suggested with those that would obtain had policymakers followed the rule in real time. Section 3 decomposes the resulting differences into their inflation and output gap components. The magnitude of the revisions for the policy recommendation is computed for four quarters following the quarter for which the policy recommendation would have applied. Section 4 discusses the effect of data revisions on estimation of simple policy rules that attempt to fit actual policy retrospectively. Estimates obtained by using the ex post revised data are compared to those obtained by using the data actually available at the time policy was formulated. Section 4 also provides estimation results for alternative specifications which vary the horizon of the inflation and output gap, and evaluates forward as opposed to contemporaneous and backward looking policy reaction functions. Section 5 provides some concluding remarks.

\section{Reconstructing Taylor's Rule}

The policy rules I examine specify that the Federal Reserve set the federal funds rate as a linear function of inflation and the output gap. Letting $\pi$ denote inflation and, $y$ the output gap, these rules take the simple form:

$$
R=a_{0}+a_{\pi} \pi+a_{y} y
$$


where $R$ is the recommended level for the federal funds rate.

The properties of such rules were first examined in some detail as part of the policy regime evaluation project reported in Bryant, Hooper and Mann (1993). The project compared the performance of simple interest rate policy rules across several empirical macroeconomic models with each rule setting the deviation of the nominal interest rate, $R$, from a baseline path, $R^{*}$, as a linear function of the deviation of a target variable, $X$, from its target, $X^{*}$,

$$
R-R^{*}=\theta\left(X-X^{*}\right)
$$

Four alternative targets were examined. Of these, three targeted a single concept, either the exchange rate, a narrow monetary aggregate or nominal income. The fourth, referred to as real-output-plus-inflation targeting, targeted a combination of real output deviations from its baseline path - the output gap — and inflation deviations from its target, $\pi^{*}: 4$

$$
R-R^{*}=\theta y+\theta\left(\pi-\pi^{*}\right) .
$$

The simulation results presented in the volume indicated that rules of this type were generally more successful in stabilizing real output and inflation than the alternative rules which targeted the exchange rate, money or nominal income.

In an influential paper advocating the usefulness of considering this type of rules for policy design, Taylor (1993) proposed a specific parameterization that has received considerable attention. Taylor set the baseline nominal interest rate to equal the sum of the "equilibrium" real rate, $r^{*}$, and inflation,

$$
R_{t}=r^{*}+\pi_{t}+\theta\left(\pi_{t}-\pi^{*}\right)+\theta y_{t}
$$

where $y_{t}$ is the output gap in quarter $t$ (measured as the percent deviation of real GDP from a baseline path reflecting the growth of potential output) and $\pi_{t}$ is the rate of change of the implicit output deflator over the previous four quarters. Taylor computed the output

\footnotetext{
${ }^{4}$ This was motivated by the "stated dual objective of many central banks to achieve a sustainable growth in real activity while avoiding inflation," (Bryant, Hooper and Mann, 1993, p. 225). Although the baseline rule set equal weights, $\theta$, for the response of the rule to inflation and the output gap, rules with unequal weights were also examined.
} 
gap by fitting a log-linear trend through real GDP. He set the response coefficient, $\theta$, to one half and assumed that both the inflation target and equilibrium real rate equaled two percent. Substituting these values in (1) and collecting terms gives:

$$
R_{t}=1+1.5 \pi_{t}+0.5 y_{t}
$$

Although Taylor offered his parameterization as a hypothetical rule that was representative of the rules examined in the model simulation work, he also noted that since 1987 it described actual Federal Reserve policy surprisingly accurately. Because of this accuracy his rule has received considerable attention in the financial press and has been much discussed by academics, policymakers, and financial practitioners. Further, his particular parameterization has been seen, not simply as a guidepost to policy decisions, but also as a useful benchmark for predicting future policy, as well as judging whether current policy has been appropriately set. ${ }^{5}$

Operational implementation of such a rule, however, entails a significant information burden; specifically it requires timely and accurate information regarding nominal output, real output and the path of potential output. Unfortunately, none of these concepts is known with much accuracy until several quarters or perhaps years later. With regard to the measurement of nominal output and the implicit output deflator, data first become available in the month following the end of a quarter and are frequently substantially revised in subsequent quarters, although the initial revisions are typically much larger than subsequent ones. With regard to the measurement of potential output, estimates obtained with subsequent revisions of the underlying data tend not to vary much from quarter to quarter but revisions tend to persist and even become amplified several quarters later. Estimation of potential output for the most recent quarter is notoriously inaccurate, especially

\footnotetext{
${ }^{5}$ By contrast, interest in alternative parameterizations of real output plus inflation targeting rules with more aggressive response coefficients, such as proposed by Henderson and McKibbin (1993), appears primarily in normative research concerning policy regime evaluation. Although comparative simulations typically find that the larger response coefficients lead to more stable inflation and output outcomes on average (e.g. Levin [1996], Orphanides et al [1997], Williams [1997]), the resulting interest rate variability is also considerably greater and implies that the non-negativity constraint on nominal interest rates may become binding for realistic inflation targets. Orphanides and Wieland (1997), provide an evaluation of this issue.
} 
around business cycle turning points when the information might be of greatest value. ${ }^{6}$

Consequently, the recommendation suggested by the rule for a specific quarter $t$, may vary considerably from quarter $t$ to quarter $t+1$ and subsequent quarters. What appears as appropriate policy consistent with the numeric rule in one quarter may be termed to have been inappropriately easy or tight with the benefit of hindsight. And, in evaluating our understanding of the driving forces for monetary policy, what appears in hindsight to best "explain" policy decisions may be dominated by alternatives that become clouded once information not available at the time those decisions were made is tacked on.

To quantify the effect of these informational problems, I constructed a database which could be employed to evaluate rules such as Taylor's in real time, and which could be used to track revisions which would follow in the few subsequent quarters. Three ingredients are needed for this exercise. Estimates of nominal output, estimates of real output and estimates of potential output. For each, it is necessary to track the value of the variable for quarter $t$ in different quarters. Doing so requires some added notation. For any variable $X$, I use the standard notation $X_{t}$ to denote the "true" value for the variable $X$ in quarter $t$ which may or may not become completely known eventually. To keep track of different vintages of data, I then let $X_{t \mid t+i}$ denote the estimate of $X_{t}$ that is available in quarter $t+i$. Thus, for a variable which is first announced with a one-quarter lag, $X_{t \mid t+1}$ represents the first available estimate.

Two additional complications are present. First for the inflation and output variables of interest, the contemporaneous estimate, $X_{t \mid t}$, represents a forecast. As a result, reconstructing Taylor's rule in real time requires a consistent set of forecasts, presumably available and relevant for monetary policy in real time. Second, since information is updated more or less continuously in time, multiple revisions of a variable within a given quarter may be available. This structure necessitates greater specificity in denoting when within a quarter $t+i$ the updated value regarding $X_{t}$ becomes available. For the purposes of this study, I rely on

\footnotetext{
${ }^{6}$ Kuttner(1992) discusses the extent of this problem and its policy implications for the United States. St-Amant and van Norden (1997) report similar difficulties for Canada.
} 
the information available in the Federal Reserve staff's macroeconomic forecasts to obtain within quarter forecasts for nominal and real output. These forecasts are presented in a document that is prepared for the FOMC before each FOMC meeting - the Greenbookwhich becomes publicly available with a five-year lag. In the period relevant for this study, the FOMC met eight times a year, typically in the months of February, March, May, July, August, September, November and December. ${ }^{7}$ For the purpose of tracking quarterly updates, I use the Greenbooks corresponding to the February, May, August and November meetings. This choice has the following advantages. First, the dates always correspond to information available by (the beginning of) the middle month of a quarter. As a result, the constructed quarterly observations are spaced approximately equally apart in time. ${ }^{8}$ For rules such as Taylor's, which are specified at a quarterly frequency and which recommend that the policy maker set the average federal funds rate in a quarter using within quarter information, the middle of the quarter is more appropriate than either the beginning or the end for evaluating a prescription presumed fixed for the whole quarter. ${ }^{9}$ Second, with this timing, the Greenbook forecasts for a quarter, $t$, always follow the announcement of the first NIPA output estimate for the previous quarter, $t-1$, at least for the sample relevant for this study. Consequently, moving from quarter to quarter, the NIPA data are of comparable accuracy relating to the completeness of the underlying information available.

In figure 1 I reconstruct Taylor's rule for the period 1987:1 to 1992:4. First, to match Taylor's rule as originally published, I use NIPA data available at the time Taylor first presented his work, as of January 1993 following the first estimate for the fourth quarter of 1992. That is, based on my timing convention, I use data as of 1993:1, corresponding to

\footnotetext{
${ }^{7}$ Occasionaly, the "February" and "July" meetings actually take place at the end of January and June, respectively.

${ }^{8}$ Indeed the timing of the meetings does not permit constructing a quarterly dataset with approximately equally spaced apart observations corresponding to the beginning or end of a quarter.

${ }^{9}$ Using the beginning of the quarter would not allow the policy maker to react to that quarter's data at all. Using the end would allow for more of the contemporaneous information to influence the rule but would make setting the average federal funds rate for the quarter at the recommended level virtually impossible.
} 
the information in the February Greenbook. ${ }^{10} \mathrm{I}$ compute the rule as:

$$
R_{t \mid 93: 1}^{T}=1+1.5 \pi_{t \mid 93: 1}+0.5 y_{t \mid 93: 1}^{T}
$$

where $\pi_{t \mid 93: 1}$ is the implicit output deflator inflation as of 1993:1, and $y_{t \mid 93: 1}^{T}$ the output gap based on real output data as of 1993:1 and using Taylor's assumption regarding the level and growth rate of potential output. ${ }^{11}$ Summary statistics for the underlying data are presented in table 1. The resulting rule is represented by the dotted line in the top panel of figure 1. As noted by Taylor, the rule appears to fit the actual data for the quarterly average level of the federal funds rate over this period surprisingly well. (The actual fed funds rate is shown by the solid line.)

As this rule was based on data which would be expected to undergo revisions, I also attempted to reconstruct Taylor's rule using data at a date sufficiently later to eliminate substantial additional revisions. Taylor (1994) provided a benchmark for such a later reconstruction (based on the revised data and a reestimated potential output concept.) Using NIPA data as of November 1994, I reconstructed this rule as: ${ }^{12}$

$$
R_{t \mid 94: 4}^{T}=1+1.5 \pi_{t \mid 94: 4}+0.5 y_{t \mid 94: 4}^{T}
$$

This is shown as the dash-dot line in the top panel of figure 1. As can be seen this variant of the rule also tracks the actual fed funds rate quite well. Confirming the prior that revisions in the data might alter the picture slightly, however, some discrepancies between the 1993 and 1994 versions of the rule become evident for the rule recommendations regarding 1992 .

Having reconstructed Taylor's rule as originally presented by him, the next step is to construct its real-time equivalent. As already alluded to, real-time data differ from what was used to compute Taylor's rule in three ways. First, in any quarter the price and output gaps are calculated with measurement concepts in use at the time rather than what Taylor used, namely GDP in 1987 dollars for all observations. Thus, before 1992, GNP and not

\footnotetext{
${ }^{10}$ This data appears to provide the best match with the data presented in figures 2 and 3 of Taylor's paper.

${ }^{11}$ The superscript $\mathrm{T}$ is used to differentiate between the output gap and resulting policy rule based on Taylor's assumptions regarding potential output and the alternative measure discussed later on.

${ }^{12}$ Using this data provides a match to the policy rule presented in figure 2 of Taylor (1994).
} 
GDP is the measure of output; and the deflator uses 1982 rather than 1987 prices. Second, for each quarter, the data reflect unrevised, contemporaneous forecasts of the output gap and inflation for that quarter. Thus, they do not incorporate information that was not available and could therefore not influence policy decisions. Finally, construction of the output gap reflects a real-time estimate of potential output, and is therefore based on different assumptions than those used by Taylor in 1993.

This last difference requires some additional explanation. Since Taylor's estimate of potential was based on log-linear detrending of output starting in 1984 and ending in 1992, his method could not be replicated in real time without some modification. Fixing the start of the sample in 1984 would produce estimates too inaccurate to be useful early on, e.g. for 1987. Clearly, the sample would be too short. And for later years, the results would be unduly influenced by the character of the 1990 recession. Rolling the start of the detrending period backwards presents an equally serious problem. For the early part of the sample, the start would coincide with the unusually deep 1981/82 recession and would for that reason skew the estimates in a predictable fashion. ${ }^{13}$ To circumvent these problems, for an estimate of potential output, I use the $Q^{*}$ series which was prepared at the time at the Federal Reserve. This experimental estimate of potential output, was constructed according to the method outlined in Clark (1982) and Braun (1990). ${ }^{14}$ As a compatibility check between Taylor's assumptions regarding potential output and $Q^{*}$, before constructing the $Q^{*}$ based rule using real-time data, I compared the potential output series and resulting policy rules using the revised data. The bottom panel of figure 1 plots the results obtained from:

$$
\begin{aligned}
& R_{t \mid 93: 1}=1+1.5 \pi_{t \mid 93: 1}+0.5 y_{t \mid 93: 1} \\
& R_{t \mid 94: 4}=1+1.5 \pi_{t \mid 94: 4}+0.5 y_{t \mid 94: 4}
\end{aligned}
$$

\footnotetext{
${ }^{13}$ Illustrative of these complications is the fact that the addition and revision of a year's worth of data changes the trend estimate for the period from 1984 to the end 1992 or 1993 by about 0.1 percent.

${ }^{14}$ From 1988 to 1994 the constructed $Q^{*}$ series was routinely updated and used as a key ingredient in the $P^{*}$ model of inflation (Hallman et al $(1989,1991)$ ). The associated historical data employed in computing $P^{*}$ were also updated and made available on request over this period. Kuttner (1994), presents a comparison of $Q^{*}$ with alternative concepts.
} 
where $y_{t \mid 93: 1}$ and $y_{t \mid 94: 4}$ are constructed using the $Q^{*}$ series available in 93:1 and 94:4 respectively. As can be seen by comparing the top and bottom panels of the figure, the rules obtained using Taylor's potential and $Q^{*}$ are essentially identical except for an intercept shift. Indeed, as shown in table 2, on average from 1987 to 1992 the difference between $R_{t \mid 94: 4}^{T}$ and $R_{t \mid 94: 4}$ has been 47 basis points but the standard deviation has been very small, merely 6 basis points, with the mean absolute demeaned difference only 5 basis points. The larger difference in the intercept reflects the fact that by construction, while the detrending methodology used by Taylor defines potential such that it equals actual output, on average, the $Q^{*}$ methodology allows potential to exceed actual output, on average. Hence, comparing the corresponding rules requires an adjustment in the intercept of the rule, equal to one half the difference of the average output gaps. Beyond this adjustment, however, the differences appear to be inconsequential. ${ }^{15}$

Using the within quarter forecasts from the Greenbook, and the $Q^{*}$ measure of potential, I constructed the real-time Taylor rule as:

$$
R_{t \mid t}=1+1.5 \pi_{t \mid t}+0.5 y_{t \mid t}
$$

Figure 2 compares the resulting real-time rule (solid line) with the actual fed funds rate (dash line) and the comparable rule obtained using the revised data (dotted line). As is apparent from the figure, the prescription obtained from the rule using the real-time data does not appear to have tracked the actual federal funds rate nearly as closely as the formulation based on the ex post revised data suggested. In fact, the prescription resulting from the real-time data appears to have been consistently lower than the actual federal funds and exhibits somewhat greater volatility. The difference in the average level of the rule prescription from the real-time data to the formulation based on the ex post revised data is mainly due to differences in the estimates of the output gap. From table 1, the mean of the real-time output gap estimate, $y_{t \mid t}$, is -1.25 percent while the mean of the estimate

\footnotetext{
${ }^{15} \mathrm{I}$ did not make this adjustment because the average difference between $y_{t \mid 94: 4}^{T}$ and $y_{t \mid 94: 4}$ could only be computed ex post and would not have been known in real-time. To avoid the resulting unnecessary complications, I concentrate on comparing the ex post and real-time versions of the rule using only the $Q^{*}$ concept of potential. As shown below, an additional bias is present when the real-time data are employed.
} 
based on 1994 data, $y_{t \mid 94: 4}$, is -.23 , a difference of one percentage point. The differences in volatility are due to the greater volatility of both the real time inflation and output gap measures relative to the revised data used for the original formulation. This is evident by comparing the standard deviations shown in table 1 . Figure 3 presents the underlying inflation and output gap data that correspond to the two alternative renditions of the rule shown in figure 2 .

As can be seen from the statistics shown in table 2, the differences in what the rule appears to recommended in real time, $R_{t \mid t}$, and what would be believed to have been recommended based on the revised data, $R_{t \mid 94: 4}$ can be substantial. The standard deviation of this difference is 58 basis points with the maximum difference approaching a staggering 200 basis points. Regarding the fit of the rule, the standard deviation between the actual federal funds, $f_{t}$, and the rule based on the revised data, $R_{t \mid 94: 4}$, is 52 basis points. The corresponding standard deviation with the real-time data, $R_{t \mid t}$, rises to 68 basis points. For comparison, note that the standard deviation of the quarterly change in the federal funds rate over this period is only 54 basis points. That is, from a positive viewpoint, a one quarter ahead forecast of the federal funds rate which naively specified that the rate would stay unchanged would be more accurate than the forecasts obtained by a contemporaneous observer having at his disposal the within quarter Greenbook forecasts and using the rule.

Besides identifying such differences, another implication from the comparison between the real-time and ex post revised renditions of the rule regards the historical interpretation of differences between Taylor's rule and actual policy. Viewing these differences as "residuals," it has been tempting to provide explanations for them much as it is tempting to provide explanations for the residuals in any model. For instance, some observers have noted that one of the most pronounced departures of actual policy from the rule occurred during the early phases of the current expansion starting in 1992. This departure has been attributed to the fact the Fed responded to the so-called "financial headwinds" facing the economy at the time by holding the federal funds rate below where it would have been held in the absence of such special factors. Since such considerations are absent from the rule, such a departure 
from the rule could be termed, in retrospect, to have been quite appropriate. Yet, looking at the rule based on the real-time data appears to contradict the premise of this argument. Indeed, throughout 1992, the federal funds rate was higher than would be suggested by the Taylor rule. The residual is of the wrong sign. Removing any additional response due to "financial headwinds" would only make matters worse. The missing element, in this case, is that in real time the recovery of output coming out of the recession in 1992 looked considerably worse than the picture painted after several subsequent revisions of the data. ${ }^{16}$

\section{$3 \quad$ Within Year Revisions}

Identifying differences between the rules evaluated in real time as compared to many years later may not be of great practical relevance if the recommendations suggested by the rule do not change drastically within a few quarters of the corresponding policy decision. A policymaker would likely be more concerned about realizing that policy was "incorrectly" set within the period the impact of this policy could still be changed.

To evaluate the extent of such revisions in the rule prescriptions, I used the real-time data to track the recommendation obtained from the rule for four quarters subsequent to the quarter for which the rule applied. That is, I constructed the revised estimates $\pi_{t \mid t+i}$ and $y_{t \mid t+i}$ for $i \in\{1,2,3,4\}$ and used them to construct the corresponding rules,

$$
R_{t \mid t+i}=1+1.5 \pi_{t \mid t+i}+0.5 y_{t \mid t+i} \text { for } i \in\{1,2,3,4\}
$$

An envelope of the results for the rule reflecting the minimum and maximum recommendation for a given quarter obtained by using the rules with $i \in\{0,1,2,3,4\}$ is shown in figure 4. As can be seen, considerable uncertainty regarding the correct setting of the rule is present within a year of the quarter for which the policy decision must be made. Figure 5 shows the ranges of the change in the rule recommendation and the corresponding changes in the underlying inflation and output gap estimates.

\footnotetext{
${ }^{16}$ It may be worthwhile noting in this context that the end of the recession, in March 1991, was not officially recognized by the NBER until December 1992. Throughout 1992, some ambiguity lingered on.
} 
Tables 3 and 4 present some statistics associated with these revisions. Table 3 shows the quarter-by-quarter revisions in the output gap and inflation while table 4 presents the cumulative revisions from the quarter the policy would have to be set for the two components of the rule as well as the rule itself.

As can be seen in the top panel of table 3, the standard deviation of the first revision of the output gap is quite large, 66 basis points. However, as this incorporates the error associated with the fact that the quarter $t$ estimate reflects a within-quarter forecast, it may not be surprising. More surprising is that the standard deviations of subsequent revisions are also quite large. For instance, the revision from $t+3$ to $t+4-$ a full year after the quarter is over - has a standard deviation of 48 basis points.

Since revisions in the output gap could reflect revisions of either real output or potential output (or both), it is useful to assess the contribution of revisions in real output alone as this component of the revision would not be affected by the choice of methodology for constructing potential output. To do so, note that the output gap can be approximated in terms of the natural logarithms of actual real output, $Q_{t}$, and potential output, $Q_{t}^{*}$ as:

$$
y_{t} \approx 100\left(\log Q_{t}-\log Q_{t}^{*}\right)
$$

Letting $q_{t}=100 \log Q_{t}$, and $q_{t}^{*}=100 \log Q_{t}^{*}$, yields the approximate decomposition of the revision of $y_{t}$ from quarter $\tau$ to quarter $\tau+1$ :

$$
y_{t \mid \tau+1}-y_{t \mid \tau} \approx\left(q_{t \mid \tau+1}-q_{t \mid \tau}\right)-\left(q_{t \mid \tau+1}^{*}-q_{t \mid \tau}^{*}\right)
$$

Therefore, the changes $\left(q_{t \mid \tau+1}-q_{t \mid \tau}\right)$ measure the size of output gap revisions that would obtain if estimates of potential output were held fixed. The resulting statistics in the second panel of table 3 reveal that the revisions to real output alone can explain most of the variation in the revisions of the output gap.

The remaining two panels of table 3 show the corresponding information for inflation. Despite substantial variability in the initial revisions of the quarterly inflation rate, $\pi^{Q}$, the variability of revisions of inflation over four quarters, $\pi$, is smaller than that of revisions of the output gap. 
The cumulative impact of these revisions to the rule's prescription, shown in table 4 , is substantial. The difference between the recommendation of the rule obtained in the quarter for which the rule applies and the revised setting suggested four quarters later has a standard deviation of 67 basis points. The maximum difference is 170 basis points.

An important observation is that substantial revisions in the rule's prescriptions for a given quarter can be expected not only in the quarter subsequent to the quarter for which the prescription is relevant, but also later on. Recalling that the first revision of the rule, $R_{t \mid t+1}$, is not based on forecasts, but is based on the actual preliminary data releases, it is clear that much of the uncertainty concerning the appropriate prescription is due to actual data revisions. This observation is important as it suggests that operational variants of Taylor's rule which are specified to respond to lagged inflation and output data are subject to the same informational problems. Indeed, the difference appears to be simply a matter of degree.

\section{Estimated Reaction Functions}

This section turns to estimating simple policy reaction functions similar in nature to the policy rules described thus far. Returning to the general family of real-output-plus-inflation targeting rules:

$$
f_{t}=a_{0}+a_{\pi} \pi_{t}+a_{y} y_{t}
$$

estimation of the response parameters, $a_{\pi}$ and $a_{y}$, would also permit examining whether parameterizations other the Taylor's might describe the actual path of the federal funds rate over the period in question at least as well.

Unfortunately, the number of observations available is rather small to allow for accurate estimation of a reaction function. Despite this problem, comparison of the estimates obtained with the ex post revised data to those obtained with the real-time data might at least permit an evaluation of whether estimates obtained with the revised data do great violence to the nature of the estimated policy rule.

To examine this issue I estimate the policy reaction function above using the alternative 
vintages of data. Also, recognizing that the Fed appears to have been smoothing interest rates over this period, I embed the reaction function above as a notional target in a partial adjustment specification, ${ }^{17}$

$$
f_{t}=\rho f_{t-1}+(1-\rho)\left(a_{0}+a_{\pi} \pi_{t}+a_{y} y_{t}\right) .
$$

Table 5 presents least squares estimates of this policy reaction function. The top panel provides estimates of the specification without partial adjustment (restricting $\rho=0$ ). The first four columns show estimates obtained by using the revised data from 1993 and 1994 based on the detrended output assumption for potential (columns 1 and 2) and on $Q^{*}$ (columns 3 and 4). The fifth column employs the real-time data. As can be seen, and confirming what was already evident to the naked eye in figure 1, using the ex post revised data yields an inflation response close to 1.5 and an output gap response close to 0.5. This is not the case when the real-time data are employed. The policy reaction function appears quite different with a considerably lower response to inflation and a worse fit. And the difference becomes more pronounced with the partial adjustment specification shown in the bottom panel of the table. The large and tight estimates of the partial adjustment coefficient $\rho$, also confirms considerable interest rate smoothing.

A potential problem with the estimates shown in table 5 is that the error term, which reflects discretionary deviations of policy from the specified policy rule, may be correlated with the contemporaneous quarter output gap and/or inflation. To verify that the results shown in table 5 are not subject to simultaneity bias, table 6 presents instrumental variables (IV) estimates of the regressions. As instruments, I use four lags of the federal funds rate as well as of the inflation and output gap corresponding to the vintage of data employed in the regression. The results are very similar to those obtained with least squares estimation.

A disturbing result from the two tables is that the inflation coefficient estimated with the real-time data is nowhere near one and could well equal zero. This result would suggest-if

\footnotetext{
${ }^{17}$ Yet, this specification retains the assumption that the policy response to inflation and output can adequately be captured with a linear function, contrary to perhaps equally plausible alternatives such as the non-linear rules described in Orphanides and Wilcox (1996).
} 
one were prepared to take this policy reaction function seriously-that monetary policy over the estimation period might have led to an unstable inflation process. ${ }^{18}$

But a more likely explanation is that the policy reaction function is not specified properly. In particular, in asserting that the FOMC sets the federal funds rate by responding to the current quarter outlook of activity and inflation from four quarters earlier to the current quarter, the policymakers are restricted to appear myopic. Rather, since monetary policy operates with a lag, successful stabilization policy needs to be more forward looking and estimated policy reaction functions should at least accommodate as much. Indeed, as Chairman Greenspan explained in a recent testimony: "Because monetary policy works with a lag, it is not the conditions prevailing today that are critical but rather those likely to prevail six to twelve months, or even longer, from now. Hence, as difficult as it is, we must arrive at some judgment about the most probable direction of the economy and the distribution of risks around that expectation." (January 21, 1997 testimony by Chairman Greenspan before the Senate Committee on the Budget.)

The possibility that policy might be more appropriately described as forward looking has attracted increased attention since early 1994 following the so-called pre-emptive strike against inflation that year. But it would be erroneous to presume that policy has been forward looking only since this most recent episode. Some recent research has already begun to sort out whether monetary policy has been forward looking or backward looking in the past, especially since the 1980s. ${ }^{19}$ In principle, doing so would require employing a time series of the Federal Open Market Committee's own outlook. Unfortunately high frequency consistent data on such forecasts are not available.

For the most part, estimation of the forward looking specifications has relied on instrumental variables estimation techniques using the actual (and ex post revised) data. Although such techniques can provide consistent estimates in large samples (once the addi-

\footnotetext{
${ }^{18}$ Henderson and McKibbin (1993), and Clarida, Gali and Gertler (1997a), find that $a_{\pi}>1$ is required for stability in model economies with monetary policy rules of this type.

${ }^{19}$ Most recently, Clarida, Gali and Gertler (1997a), investigate forward looking reaction functions such as the ones examined here. Clarida and Gertler (1997), find such rules useful for describing German monetary policy as well.
} 
tional assumption that expectations are formed rationally is imposed), the added noise in the data may render distinguishing among backward, contemporaneous and forward looking rules difficult in small samples. Here, I illustrate some of these difficulties by comparing estimated reaction functions using both the ex post revised and the real-time data for the 1987-1992 period. For the forward looking variants of the estimated policy reaction functions, I employ forecasts from the same Greenbooks I use to assess the within quarter outlook used to construct Taylor's rule in real time. ${ }^{20}$ To be noted, these forecasts may not represent the views of the FOMC and suffer from a serious problem in that they are conditioned on a specific policy path which may not necessarily coincide with the path consistent with the Committee's outlook for policy. Despite this problem, they may provide as useful proxies for the appropriate forecasts as is feasible with the data currently available.

The policy reaction functions I estimate take the form:

$$
f_{t}=\rho f_{t-1}+(1-\rho)\left(a_{0}+a_{\pi} \pi_{t+i \mid t}+a_{y} y_{t+i \mid t}\right)
$$

Here, $i$ reflects the "target" horizon relative to the quarter at which the federal funds rate is decided. For Taylor's rule the relevant horizon is the present quarter, $i=0$. The estimates shown earlier in tables 5 and 6 correspond to this case. For forward looking alternatives $i>0$. I examine horizons ranging from 1 to 4 quarters ahead. For completeness, I also estimate a backward looking policy reaction function for $i=-1$. This latter reaction function is of some interest because this timing implies reacting to the most recent available data (for the previous quarter) which renders the rule operational without reliance upon forecasts. ${ }^{21}$

Estimation results are shown in tables 7,8 and 9 . Tables 7 and 8 present estimates based on the real-time data using least squares and IV estimation, respectively. Table 9

\footnotetext{
${ }^{20}$ Use of Greenbook forecasts in estimating reaction functions was introduced by McNees (1986). Romer and Romer (1996) find these forecasts to be quite accurate relative to alternative private forecasts.

${ }^{21}$ If, as Meltzer (1987) argues, forecasts are too inaccurate to be useful for monetary policy decisions, and policy is formulated in terms of recent economic outcomes, such backward looking rules might provide a better description of policy. However, since a monetary aggregate could be a superior intermediate target in that case, it might also prove a better policy indicator than the lagged output and inflation measures examined here.
} 
presents estimates based on the final data using IV estimation. When IV is employed, I use four lags each of the federal funds rate, inflation and the output gap as instruments, the same instruments used in the Taylor-type reaction functions estimated in table $6 .^{22}$

As with the within-quarter estimates of inflation and output, the forecasts employed in the regressions using the real-time data are based on information contemporaneous with the policy setting. Since the appropriateness of least squares is not entirely clear, both least squares and IV estimates are shown. The results appear similar but I concentrate attention on the IV estimates shown in table 8 as the estimation technique makes them more comparable to the results based on the revised data shown in table 9 . The Taylortype regression using the real-time data in table 5 is replicated in the second column of the table $(i=0)$. As observed earlier, this specification yields an estimate of the response to inflation that is uncomfortably low. Concentrating, as before, on the partial adjustment specification in the lower panel, shows a point estimate for the contemporaneous horizon that is essentially zero. A quick look across the different columns, however, reveals that this result is not shared with the forward-looking specifications. Indeed, looking at the three- and four-quarter ahead horizons suggests point estimates of $a_{\pi}$ surprisingly close to the 1.5 value Taylor specified in his rule, and significantly greater than one. The output gap response, $a_{y}$, is also large in magnitude and tightly estimated, with the point estimates higher than the 0.5 value in Taylor's rule. In addition to the sensible point estimates provided by the forward-looking specifications compared to the contemporaneous and backward-looking specifications, the fit of the equations is also somewhat better. Overall, estimation based on the real-time data suggests that forward-looking policy rules provide a somewhat more accurate and reasonable description of monetary policy than their contemporaneous and/or backward-looking counterparts. But the data over this period cannot clearly distinguish among the alternative forward horizons.

In table 9, I present IV estimates based on the ex post revised data as of 1994, us-

\footnotetext{
${ }^{22}$ For the backward looking policy reaction function (column 1), least squares estimates are always shown.
} 
ing the $Q^{*}$ concept for potential output. ${ }^{23}$ As before, I use four lags each of the federal funds rate, inflation and the output gap as instruments. Comparing the fitted reaction functions corresponding to the different horizons reveals some interesting regularities. As with the real-time counterparts of these regressions, the point estimate of $a_{\pi}$, the coefficient reflecting the response to inflation, generally rises as the horizon becomes forward. Looking at the bottom panel (the partial adjustment specification) the estimate changes from being (insignificantly) negative for the backward looking specification to exceeding 3 for the four-quarter ahead horizon. Also, with the exception of the four-quarter ahead horizon specification (which is not estimated at all precisely), the point estimates of $a_{y}$, drops as the horizon becomes more forward. Overall, however, the forward looking specifications do not seem to fit the data as well as the Taylor-type contemporaneous reaction function. (As with the real-time estimates, however, the contemporaneous specification is an improvement over its backward-looking counterpart.) Indicative of this deterioration is that $\rho$, the partial adjustment coefficient estimate, increases with the horizon, indicating that as the horizon lengthens, the lag of the federal funds rate serves, in part, increasingly as a proxy for the imperfectly specified output and inflation variables. ${ }^{24}$

One can conclude that analysis based on the ex post revised data instead of the data available in real time over this sample could easily overshadow the fact that forward looking policy reaction functions appear to provide a more accurate description of policy than Taylor-type contemporaneous specifications.

\section{Conclusion}

Quantitative evidence suggesting that monetary policy guided by simple rules achieves good results in simulated models of the macroeconomy continues to accumulate. Thus, simple rules appear to offer useful baselines for policy discussions. The discussion, however, often does not place proper emphasis on the informational problem associated with some of the

\footnotetext{
${ }^{23}$ Only IV estimates are shown as least squares are clearly inappropriate for the forward looking specifications in this case.

${ }^{24}$ This result is possible because both inflation and the output gap are positively serially correlated.
} 
advocated policy rules. This paper examines the magnitude of this informational problem. The evidence suggests that it is substantial.

Reactive policy rules that require the policymaker to respond to macroeconomic conditions which are difficult to assess in practice, involve much greater uncertainty than is often recognized. Using Taylor's rule as an illustration, I evaluated the extent to which the rule's recommendations would change with incoming data. Over the 1987-1992 period, the standard deviation of within-year revisions of the recommendation obtained by the rule for a specific quarter exceeded the standard deviation of the quarterly change in the federal funds rate. Further, while the rule may appear to describe actual policy fairly accurately when the ex post revised data are employed, it does not provide nearly as accurate a picture if real-time data are used to construct what the rule would have recommended when policy was actually set.

Taking account of the information problem documented here may cloud some of the encouraging results arguing in favor of policy adhering to such rules. One of the reasons simple rules are believed useful is that they can provide the policymaker with the flexibility to achieve some of the benefits of discretionary short-run stabilization policy while retaining credibility towards the long-term goal of price stability. The rationale is that since simple rules are easy to evaluate, departures from the rules would be easily detectable. As long as policy moves in accordance with a rule, credibility is maintained. But disagreements over the current economic outlook or the likely direction of pending data revisions can make it difficult to assess whether policy deviated from or was set in accordance with an agreedupon fixed policy rule. Implementation of supposedly transparent feedback rules may be anything but simple.

It would be tempting to argue that rules based on data that are not subject to substantial revisions might be immune to these problems. For instance, the rate of unemployment and CPI inflation are available on a monthly basis, within a few weeks of the end of the relevant month, and are not revised, save for relatively minor changes involving updating of seasonal factors. Even reliance on these variables, however, would not be truly free 
from the uncertainties due to data revisions. With regard to the unemployment rate, for instance, the relevant measure for policy would likely be its level relative to the natural rate - the unemployment gap. As recent experience suggests, the estimation of that concept is subject to considerable uncertainty. With regard to CPI inflation, the relevant measure for policy would likely attempt to account for any suspected measurement bias. Again, as recent experience suggests, estimates of this bias can be quite uncertain and likely change over time. Further, the fact that a variable is subject to fewer revisions is not necessarily a reflection of more accurate timely measurement. As well, it could reflect permanent mismeasurement, one that the statistical agency providing the information never intended to improve upon.

Reliance on ex post revised data can also prove quite misleading in attempts to identify the historical pattern of policy by estimating monetary policy reaction functions. In small samples, the problem is likely to be more severe when the true structure of the policy reaction function is forward looking in which case estimation relies on lagged ex post revised data as instrument for the policymakers' forecasts upon which policy was actually based. Needless to say, identification of monetary policy shocks under such circumstances becomes a haphazard enterprise. First because use of revised data may lead to inadvertent misspecification of the estimated policy rule. And second, because even with a fixed estimated reaction function, estimates of the resulting policy shocks may vary substantially with subsequent vintages of data. When an estimated policy reaction function is embedded in a multivariate system of the macroeconomy, as is the case with VAR models for instance, such difficulties, might seriously undermine the validity of the results.

Although the findings in this paper call for greater care in treating the informational requirements associated with the implementation and evaluation of policy rules, it would be incorrect to conclude that they provide evidence against the potential stabilization benefits of such rules. Evaluation of the performance of policy rules reacting to contemporaneous output and inflation, $y_{t}$ and $\pi_{t}$ for instance, ought to incorporate auxiliary equations reflecting the informational problem, e.g. $\pi_{t}=\pi_{t \mid t}+e_{t}^{\pi}, y_{t}=y_{t \mid t}+e_{t}^{y}$. This paper demonstrates 
that the errors in such auxiliary equations, $e^{\pi}$ and $e^{y}$, cannot be assumed away. But it also provides information on their characteristics. Once these errors are incorporated into the analysis, useful evaluation of policy rules can proceed. Moreover, the importance of this informational problem is likely to vary with the specification of the rule. Careful accounting of such differences would allow for more meaningful comparisons among alternative rules.

To the extent simple policy rules offer the promise to provide a useful baseline for improving policy decisions, a step towards clarification of their potential would be a welcome step in the right direction. 


\section{References}

Ball, Laurence. "Efficient Rules for Monetary Policy.” NBER Working paper \# 5952, March 1997.

Bernanke, Ben, and Michael Woodford. "Inflation Forecasts and Monetary Policy." Working paper, October 1996.

Braun, Steven. "Estimation of Current-Quarter Gross National Product by Pooling Preliminary Labor-Market Data," Journal of Business and Economic Statistics, 8, 1990, 293-304.

Bryant, Ralph C., Peter Hooper and Catherine Mann eds. Evaluating Policy Regimes: New Research in Empirical Macroeconomics, Brookings: Washington DC, 1993.

Clarida, Richard, Jordi Gali, and Mark Gertler. "Monetary Policy Rules and Macroeconomic Stability: Evidence and Some Theory," Working paper, March 1997a.

Clarida, Richard, Jordi Gali, and Mark Gertler. "The Science of Monetary Policy," Working paper, September 1997b.

Clarida, Richard and Mark Gertler. "How the Bundesbank conducts monetary policy," in Reducing Inflation: Motivation and Strategy Christina D. Romer and David H. Romer, eds. Chicago: University of Chicago: Chicago, 1997.

Clark, Peter K. "Okun's Law and Potential GNP," Board of Governors of the Federal Reserve System, October 1982.

Fair, Ray C. and E. Philip Howrey, "Evaluating Alternative Monetary Policy Rules," Journal of Monetary Economics, 38, 1996, 173-193.

Fuhrer, Jeffrey C. "Inflation/Output Variance Trade-Offs and Optimal Monetary Policy," Journal of Money, Credit, and Banking, 29(2), May 1997, 214-234.

Hallman, Jeffrey, Richard Porter, and David Small. "M2 per unit of GNP as an anchor for the price level," Board of Governors of the Federal Reserve System Staff Study \#157, 1989.

Hallman, Jeffrey, Richard Porter, and David Small. "Is the Price Level Tied to the M2 Monetary Aggregate in the Long Run?," American Economic Review, 81(4), September 
1991, p. $841-858$.

Henderson, Dale and Warwick J. McKibbin. "A Comparison of Some Basic Monetary Policy Regimes for Open Economies: Implications of Different Degrees of Instrument Adjustment and Wage Persistence", Carnegie-Rochester Conference Series on Public Policy (39) 221-318, 1993.

Kuttner, Kenneth "Monetary Policy with uncertain estimates of potential output," Economic Perspectives: Federal Reserve Bank of Chicago, January/February, 1992, p. 2-15.

Kuttner, Kenneth "Estimating Potential Output as a Latent Variable," Journal of Business and Economic Statistics, July 1994, 12(3) p. 361-368.

Levin, Andrew. "A Comparison of Alternative Monetary Policy Rules in the Federal Reserve Board's Multi-Country Model," BIS Conference papers Vol. 2, 1996, pp. 340-366.

Lowe, Philip, ed. Monetary Policy and Inflation Targeting, Reserve Bank of Australia, 1997.

McCallum, Bennett T. "Comment", in Evaluating Policy Regimes: New Research in Empirical Macroeconomics Ralph C. Bryant, Peter Hooper and Catherine Mann, eds., Brookings: Washington DC, 1993a.

McCallum, Bennett T. "Discretion versus Policy Rules in Practice, Two Critical Points: A Comment." Carnegie-Rochester Conference Series on Public Policy, 39, December 1993b, 215-220.

McCallum, Bennett T. "Issues in the Design of Monetary Policy." Mimeo, Carnegie Mellon University, 1997.

Meltzer, Allan H. "Limits of Short-Run Stabilization Policy" Economic Inquiry, 25, 1987, $1-14$.

McNees, Stephen K. "Modeling the Fed: A Forward-Looking Monetary Policy Reaction Function." New England Economic Review, November/December 1986, 3-8.

Orphanides, Athanasios, and David Wilcox. "The Opportunistic Approach to Disinflation." Finance and Economics Discussion Series, 96-24, Board of Governors of the Federal Reserve System, May 1996. 
Orphanides, Athanasios, and Volker Wieland. "Price Stability and Monetary Policy Effectiveness when Nominal Interest Rates are Bounded at Zero." Mimeo, Federal Reserve Board, December 1997.

Orphanides, Athanasios, David Small, David Wilcox, and Volker Wieland. "A Quantitative Exploration of the Opportunistic Approach to Disinflation." Finance and Economics Discussion Series, 97-36, Board of Governors of the Federal Reserve System, June 1997.

Romer, Christina D., and David H. Romer. "Federal Reserve Private Information and the Behavior of Interest Rates." National Bureau of Economic Research working paper 5692, July 1996.

Rotemberg, Julio and Michael Woodford. "An Optimization-Based Econometric Framework for the Evolution of Monetary Policy.” Mimeo, Princeton University, 1997.

St-Amant, Pierre, and Simon van Norden. "Measurement of the Output Gap: A Discussion of Recet Research at the Bank of Canada." Technical Report No. 79, Bank of Canada, August 1997.

Svensson, Lars E. O. "Inflation Forecast Targeting: Implementing and Monitoring Inflation Targets." European Economic Review, 41(6), June 1997, 1111-1146.

Taylor, John B. "Discretion versus Policy Rules in Practice." Carnegie-Rochester Conference Series on Public Policy, 39, December 1993, 195-214.

Taylor, John B. "The Inflation/Output Variability Trade-Off Revisited." in Goals, Guidelines, and Constraints Facing Monetary Policymakers, J. Fuhrer, ed., Federal Reserve Bank of Boston, 1994.

Williams, John. "Simple Rules for Monetary Policy." Mimeo, Federal Reserve Board, 1997. 
Table 1

Summary Statistics: 1987:1-1992:4

\begin{tabular}{lrrrrrr}
\hline \hline Name & MEAN & SD & MA & MAD & MIN & MAX \\
\hline \hline$f_{t}$ & 6.79 & 1.93 & 6.79 & 1.53 & 3.04 & 9.73 \\
$f_{t}-f_{t-1}$ & -0.13 & 0.54 & 0.45 & 0.43 & -1.32 & 0.97 \\
$\pi_{t \mid t}$ & 3.46 & 0.75 & 3.46 & 0.64 & 2.25 & 4.66 \\
$\pi_{t \mid 94: 4}$ & 3.76 & 0.68 & 3.76 & 0.60 & 2.60 & 4.71 \\
$y_{t \mid t}$ & -1.25 & 2.16 & 1.98 & 1.91 & -4.36 & 1.90 \\
$y_{t \mid 94: 4}$ & -0.23 & 1.78 & 1.57 & 1.59 & -2.99 & 2.07 \\
$y_{t \mid 94: 4}^{T}$ & 0.71 & 1.75 & 1.67 & 1.57 & -1.98 & 3.00 \\
\hline \hline
\end{tabular}

Notes: $f_{t}$ is the daily average federal funds rate for quarter $t$, in percent per year. $y_{t}$ is the output gap for quarter $t$, defined as actual real output minus potential, as a fraction of potential, in percent. $\pi_{t}$ is inflation of the implicit deflator from the same quarter in the previous year, in percent. For any variable $X, X_{t \mid t+i}$ denotes the estimate of $X_{t}$ available in quarter $t+i$. The statistics shown for each variable are: MEAN, the mean; SD, the standard deviation; MA, the mean of the absolute value; MAD, the mean of the absolute value of the variable minus its mean; and MIN and MAX, the minimum and maximum values. 
Table 2

Descriptive Statistics of Taylor's Rule: 1987:1-1992:4

\begin{tabular}{lrcrrrr}
\hline \hline Name & MEAN & \multicolumn{1}{c}{ SD } & MA & MAD & MIN & MAX \\
\hline \hline$f_{t}-R_{t \mid 93: 1}^{T}$ & -0.02 & 0.40 & 0.30 & 0.30 & -0.57 & 0.95 \\
$f_{t}-R_{t \mid 94: 4}^{T}$ & -0.20 & 0.55 & 0.45 & 0.41 & -1.62 & 0.92 \\
$f_{t}-R_{t \mid 93: 1}$ & 0.40 & 0.35 & 0.44 & 0.30 & -0.26 & 1.05 \\
$f_{t}-R_{t \mid 94: 4}$ & 0.27 & 0.52 & 0.46 & 0.39 & -1.10 & 1.26 \\
$f_{t}-R_{t \mid t}$ & 1.23 & 0.68 & 1.23 & 0.48 & 0.23 & 3.26 \\
$R_{t \mid 94: 4}-R_{t \mid t}$ & 0.96 & 0.58 & 0.96 & 0.46 & -0.07 & 1.99 \\
$R_{t \mid 94: 4}^{T}-R_{t \mid 94: 4}$ & 0.47 & 0.06 & 0.47 & 0.05 & 0.35 & 0.53 \\
\hline \hline
\end{tabular}

Notes: $R$ is Taylor's rule, constructed as explained in the text. See also notes to Table 1. 
Table 3

\section{Summary Statistics for Revisions in Output Gap and Implicit Deflator Inflation: 1987:1-1992:4}

\begin{tabular}{lrccrcr}
\hline \hline Name & MEAN & SD & MA & MAD & MIN & MAX \\
\hline \hline$y_{t \mid t+1}-y_{t \mid t}$ & 0.17 & 0.66 & 0.53 & 0.50 & -1.30 & 1.37 \\
$y_{t \mid t+2}-y_{t \mid t+1}$ & 0.11 & 0.58 & 0.40 & 0.37 & -1.12 & 1.37 \\
$y_{t \mid t+3}-y_{t \mid t+2}$ & 0.02 & 0.47 & 0.28 & 0.29 & -1.00 & 1.09 \\
$y_{t \mid t+4}-y_{t \mid t+3}$ & 0.03 & 0.48 & 0.31 & 0.32 & -0.96 & 0.94 \\
\hline$q_{t \mid t+1}-q_{t \mid t}$ & 0.15 & 0.52 & 0.41 & 0.37 & -1.33 & 1.27 \\
$q_{t \mid t+2}-q_{t \mid t+1}$ & 0.10 & 0.44 & 0.27 & 0.25 & -1.08 & 1.37 \\
$q_{t \mid t+3}-q_{t \mid t+2}$ & 0.02 & 0.39 & 0.16 & 0.18 & -0.99 & 1.09 \\
$q_{t \mid t+4}-q_{t \mid t+3}$ & 0.06 & 0.45 & 0.20 & 0.24 & -0.81 & 1.50 \\
\hline$\pi_{t \mid t+1}-\pi_{t \mid t}$ & -0.01 & 0.23 & 0.19 & 0.19 & -0.45 & 0.45 \\
$\pi_{t \mid t+2}-\pi_{t \mid t+1}$ & 0.04 & 0.20 & 0.14 & 0.14 & -0.40 & 0.47 \\
$\pi_{t \mid t+3}-\pi_{t \mid t+2}$ & -0.01 & 0.10 & 0.04 & 0.05 & -0.30 & 0.34 \\
$\pi_{t \mid t+4}-\pi_{t \mid t+3}$ & 0.04 & 0.14 & 0.07 & 0.09 & -0.25 & 0.49 \\
\hline$\pi_{t \mid t+1}^{Q}-\pi_{t \mid t}^{Q}$ & -0.13 & 0.71 & 0.59 & 0.58 & -1.55 & 1.10 \\
$\pi_{t \mid t+2}^{Q}-\pi_{t \mid t+1}^{Q}$ & 0.17 & 0.47 & 0.38 & 0.33 & -0.68 & 1.59 \\
$\pi_{t \mid t+3}^{Q}-\pi_{t \mid t+2}^{Q}$ & -0.05 & 0.31 & 0.11 & 0.15 & -1.33 & 0.57 \\
$\pi_{t \mid t+4}^{Q}-\pi_{t \mid t+3}^{Q}$ & 0.05 & 0.27 & 0.11 & 0.14 & -0.54 & 1.01 \\
\hline \hline
\end{tabular}

Notes: The first panel shows the quarter by quarter revisions in the estimate of the output gap, $y$, in percent. The second panel shows the contribution of revisions in real output, $q$, to the revisions in the output gap. The third panel shows the quarter by quarter revisions in the inflation of the implicit deflator over four quarters, $\pi_{t}$, in percent. The last panel shows the corresponding revisions of inflation from the previous quarter, $\pi_{t}^{Q}$, in percent annual rate. See also notes to Table 1. 
Table 4

\section{Summary Statistics for Revisions in Taylor's Rule and its Components:}

1987:1-1992:4

\begin{tabular}{lrrrrrr}
\hline \hline Name & MEAN & \multicolumn{1}{c}{ SD } & MA & MAD & MIN & MAX \\
\hline \hline$R_{t \mid t+1}-R_{t \mid t}$ & 0.07 & 0.46 & 0.37 & 0.37 & -0.77 & 1.12 \\
$R_{t \mid t+2}-R_{t \mid t}$ & 0.18 & 0.61 & 0.52 & 0.49 & -0.82 & 1.70 \\
$R_{t \mid t+3}-R_{t \mid t}$ & 0.18 & 0.66 & 0.57 & 0.55 & -0.82 & 1.70 \\
$R_{t \mid t+4}-R_{t \mid t}$ & 0.25 & 0.67 & 0.58 & 0.51 & -0.82 & 1.70 \\
$R_{t \mid 94: 4}-R_{t \mid t}$ & 0.96 & 0.58 & 0.96 & 0.46 & -0.07 & 1.99 \\
$R_{t \mid 94: 4}^{T}-R_{t \mid 94: 4}$ & 0.47 & 0.06 & 0.47 & 0.05 & 0.35 & 0.53 \\
\hline$y_{t \mid t+1}-y_{t \mid t}$ & 0.17 & 0.66 & 0.53 & 0.50 & -1.30 & 1.37 \\
$y_{t \mid t+2}-y_{t \mid t}$ & 0.27 & 0.78 & 0.62 & 0.63 & -1.16 & 1.75 \\
$y_{t \mid t+3}-y_{t \mid t}$ & 0.30 & 0.86 & 0.74 & 0.71 & -1.16 & 1.82 \\
$y_{t \mid t+4}-y_{t \mid t}$ & 0.33 & 0.94 & 0.83 & 0.80 & -1.16 & 2.05 \\
$y_{t \mid 94: 4}-y_{t \mid t}$ & 1.02 & 0.78 & 1.04 & 0.66 & -0.17 & 2.25 \\
$y_{t \mid 94: 4}^{T}-y_{t \mid 94: 4}$ & 0.94 & 0.11 & 0.94 & 0.10 & 0.69 & 1.06 \\
\hline$\pi_{t \mid t+1}-\pi_{t \mid t}$ & -0.01 & 0.23 & 0.19 & 0.19 & -0.45 & 0.45 \\
$\pi_{t \mid t+2}-\pi_{t \mid t}$ & 0.03 & 0.28 & 0.22 & 0.22 & -0.44 & 0.58 \\
$\pi_{t \mid t+3}-\pi_{t \mid t}$ & 0.02 & 0.26 & 0.20 & 0.21 & -0.44 & 0.58 \\
$\pi_{t \mid t+4}-\pi_{t \mid t}$ & 0.06 & 0.26 & 0.22 & 0.22 & -0.44 & 0.58 \\
$\pi_{t \mid 94: 4}-\pi_{t \mid t}$ & 0.30 & 0.30 & 0.32 & 0.22 & -0.18 & 1.11 \\
$\pi_{t \mid 94: 4}^{T}-\pi_{t \mid 94: 4}$ & 0.00 & 0.00 & 0.00 & 0.00 & 0.00 & 0.00 \\
\hline \hline
\end{tabular}

Notes: See notes to Tables 1 and 2. 
Table 5

\section{Taylor-Type Estimated Rules with Alternative Data}

\section{LS Estimation}

\begin{tabular}{|c|c|c|c|c|c|}
\hline & \multicolumn{5}{|c|}{ Vintage of data and concept of potential } \\
\hline & \multicolumn{2}{|c|}{ Trend } & \multicolumn{3}{|c|}{$Q^{*}$} \\
\hline & 1993:1 & $1994: 4$ & 1993:1 & 1994:4 & Real-Time \\
\hline \multirow[t]{2}{*}{$a_{0}$} & 1.49 & 0.68 & 1.39 & 1.04 & 4.89 \\
\hline & 0.69 & 1.27 & 0.54 & 1.16 & 1.06 \\
\hline \multirow[t]{2}{*}{$a_{\pi}$} & 1.36 & 1.51 & 1.50 & 1.57 & 0.79 \\
\hline & 0.17 & 0.31 & 0.13 & 0.28 & 0.26 \\
\hline \multirow{2}{*}{$a_{y}$} & 0.54 & 0.60 & 0.50 & 0.58 & 0.65 \\
\hline & 0.04 & 0.05 & 0.04 & 0.05 & 0.06 \\
\hline $\bar{R}^{2}$ & 0.96 & 0.92 & 0.96 & 0.93 & 0.91 \\
\hline$S E E$ & 0.41 & 0.55 & 0.37 & 0.51 & 0.57 \\
\hline \multirow[t]{2}{*}{$a_{0}$} & 2.13 & 2.06 & 1.96 & 2.49 & 7.53 \\
\hline & 1.00 & 2.08 & 0.70 & 1.83 & 3.25 \\
\hline \multirow[t]{2}{*}{$a_{\pi}$} & 1.13 & 0.99 & 1.34 & 1.15 & 0.10 \\
\hline & 0.27 & 0.61 & 0.17 & 0.47 & 0.84 \\
\hline \multirow[t]{2}{*}{$a_{y}$} & 0.74 & 1.08 & 0.68 & 0.99 & 1.07 \\
\hline & 0.12 & 0.37 & 0.07 & 0.28 & 0.40 \\
\hline \multirow[t]{2}{*}{$\rho$} & 0.49 & 0.65 & 0.47 & 0.61 & 0.65 \\
\hline & 0.12 & 0.16 & 0.07 & 0.14 & 0.19 \\
\hline $\bar{R}^{2}$ & 0.98 & 0.97 & 0.98 & 0.97 & 0.96 \\
\hline$S E E$ & 0.29 & 0.34 & 0.25 & 0.32 & 0.36 \\
\hline
\end{tabular}

Notes: The regressions shown are estimates of the equation:

$$
f_{t}=\rho f_{t-1}+(1-\rho)\left(a_{o}+a_{\pi} \pi_{t}+a_{y} y_{t}\right)
$$

The columns correspond to alternative vintages of data, as shown. In the top panel $\rho$ is restricted to zero. The standard errors shown under the parameter estimates are based on the Newey-West heteroskedastity and serial correlation robust estimator. 
Table 6

\section{Taylor-Type Estimated Rules with Alternative Data IV Estimation}

\begin{tabular}{|c|c|c|c|c|c|}
\hline & \multicolumn{5}{|c|}{ Vintage of data and concept of potential } \\
\hline & \multicolumn{2}{|c|}{ Trend } & \multicolumn{3}{|c|}{$Q^{*}$} \\
\hline & 1993:1 & $1994: 4$ & 1993:1 & 1994:4 & Real-Time \\
\hline \multirow[t]{2}{*}{$a_{0}$} & 1.58 & 0.79 & 1.43 & 1.13 & 4.77 \\
\hline & 0.69 & 1.25 & 0.55 & 1.16 & 1.04 \\
\hline \multirow[t]{2}{*}{$a_{\pi}$} & 1.33 & 1.48 & 1.49 & 1.54 & 0.82 \\
\hline & 0.16 & 0.31 & 0.13 & 0.28 & 0.26 \\
\hline \multirow{2}{*}{$a_{y}$} & 0.55 & 0.62 & 0.51 & 0.60 & 0.65 \\
\hline & 0.04 & 0.06 & 0.05 & 0.06 & 0.05 \\
\hline $\bar{R}^{2}$ & 0.96 & 0.92 & 0.96 & 0.93 & 0.91 \\
\hline$S E E$ & 0.41 & 0.55 & 0.37 & 0.51 & 0.57 \\
\hline \multirow[t]{2}{*}{$a_{0}$} & 2.67 & 3.35 & 2.38 & 3.55 & 7.85 \\
\hline & 1.18 & 2.78 & 0.70 & 2.28 & 3.65 \\
\hline \multirow[t]{2}{*}{$a_{\pi}$} & 0.97 & 0.58 & 1.23 & 0.86 & 0.01 \\
\hline & 0.33 & 0.87 & 0.17 & 0.61 & 0.94 \\
\hline \multirow[t]{2}{*}{$a_{y}$} & 0.83 & 1.31 & 0.74 & 1.16 & 1.11 \\
\hline & 0.17 & 0.57 & 0.08 & 0.39 & 0.46 \\
\hline \multirow[t]{2}{*}{$\rho$} & 0.56 & 0.71 & 0.52 & 0.67 & 0.68 \\
\hline & 0.14 & 0.16 & 0.08 & 0.15 & 0.19 \\
\hline $\bar{R}^{2}$ & 0.98 & 0.97 & 0.98 & 0.97 & 0.96 \\
\hline$S E E$ & 0.30 & 0.35 & 0.26 & 0.32 & 0.36 \\
\hline
\end{tabular}

Notes: The regressions shown are estimates of the equation:

$$
f_{t}=\rho f_{t-1}+(1-\rho)\left(a_{o}+a_{\pi} \pi_{t}+a_{y} y_{t}\right)
$$

The columns correspond to alternative vintages of data, as shown. In the top panel $\rho$ is restricted to zero. The standard errors shown under the parameter estimates are based on the Newey-West heteroskedastity and serial correlation robust estimator. 
Table 7

\section{Forward Looking Rules Estimated with Real-Time Data}

\section{LS Estimation}

\begin{tabular}{lrccccc}
\hline \hline & \multicolumn{6}{c}{ Horizon Relative to Decision Period (in Quarters) } \\
\cline { 2 - 7 } & -1 & 0 & 1 & 2 & 3 & 4 \\
\hline \hline$a_{0}$ & 6.38 & 4.89 & 4.51 & 3.95 & 1.82 & 0.84 \\
& 1.12 & 1.06 & 1.33 & 1.48 & 1.14 & 0.64 \\
$a_{\pi}$ & 0.37 & 0.79 & 0.89 & 1.03 & 1.57 & 1.83 \\
& 0.29 & 0.26 & 0.33 & 0.36 & 0.26 & 0.14 \\
$a_{y}$ & 0.79 & 0.65 & 0.64 & 0.62 & 0.53 & 0.50 \\
& 0.07 & 0.06 & 0.07 & 0.11 & 0.11 & 0.09 \\
$\bar{R}^{2}$ & 0.90 & 0.91 & 0.90 & 0.88 & 0.91 & 0.92 \\
$S E E$ & 0.62 & 0.57 & 0.60 & 0.66 & 0.58 & 0.56 \\
\hline$a_{0}$ & 12.17 & 7.53 & 6.53 & 6.86 & 5.08 & 3.22 \\
& 6.56 & 3.25 & 2.61 & 2.21 & 1.81 & 0.93 \\
$a_{\pi}$ & -1.22 & 0.10 & 0.39 & 0.32 & 0.79 & 1.29 \\
& 1.79 & 0.84 & 0.64 & 0.52 & 0.42 & 0.20 \\
$a_{y}$ & 1.53 & 1.07 & 1.02 & 1.16 & 1.09 & 1.00 \\
& 0.77 & 0.40 & 0.30 & 0.28 & 0.24 & 0.17 \\
$\rho$ & 0.78 & 0.65 & 0.63 & 0.67 & 0.65 & 0.62 \\
& 0.17 & 0.19 & 0.14 & 0.09 & 0.09 & 0.09 \\
$\bar{R}^{2}$ & 0.95 & 0.96 & 0.97 & 0.97 & 0.97 & 0.97 \\
$S E E$ & 0.41 & 0.36 & 0.34 & 0.33 & 0.33 & 0.34 \\
\hline \hline
\end{tabular}

Notes: The regressions shown are estimates of the equation:

$$
f_{t}=\rho f_{t-1}+(1-\rho)\left(a_{o}+a_{\pi} \pi_{t+i}+a_{y} y_{t+i}\right)
$$

The columns correspond to different values for $i$. In the top panel $\rho$ is restricted to zero. The standard errors shown under the parameter estimates are based on the Newey-West heteroskedastity and serial correlation robust estimator. 
Table 8

Forward Looking Rules Estimated with Real-Time data IV Estimation

\begin{tabular}{lrrrrrr}
\hline \hline & \multicolumn{6}{c}{ Horizon Relative to Decision Period (in Quarters) } \\
\cline { 2 - 7 } & -1 & 0 & 1 & 2 & \multicolumn{1}{c}{3} & \multicolumn{1}{c}{4} \\
\hline \hline$a_{0}$ & 6.38 & 4.77 & 4.60 & 3.86 & -1.94 & -1.38 \\
& 1.12 & 1.04 & 1.15 & 1.46 & 2.59 & 1.20 \\
$a_{\pi}$ & 0.37 & 0.82 & 0.87 & 1.06 & 2.51 & 2.37 \\
& 0.29 & 0.26 & 0.28 & 0.35 & 0.67 & 0.30 \\
$a_{y}$ & 0.79 & 0.65 & 0.65 & 0.62 & 0.23 & 0.30 \\
& 0.07 & 0.05 & 0.06 & 0.11 & 0.21 & 0.14 \\
$\bar{R}^{2}$ & 0.90 & 0.91 & 0.90 & 0.88 & 0.87 & 0.90 \\
$S E E$ & 0.62 & 0.57 & 0.60 & 0.66 & 0.70 & 0.60 \\
\hline$a_{0}$ & 12.17 & 7.85 & 6.52 & 6.93 & 2.36 & 1.82 \\
& 6.56 & 3.65 & 2.43 & 2.53 & 2.09 & 1.68 \\
$a_{\pi}$ & -1.22 & 0.01 & 0.39 & 0.31 & 1.46 & 1.62 \\
& 1.79 & 0.94 & 0.59 & 0.61 & 0.50 & 0.39 \\
$a_{y}$ & 1.53 & 1.11 & 1.02 & 1.16 & 0.79 & 0.82 \\
& 0.77 & 0.46 & 0.29 & 0.30 & 0.18 & 0.25 \\
$\rho$ & 0.78 & 0.68 & 0.63 & 0.67 & 0.57 & 0.56 \\
& 0.17 & 0.19 & 0.14 & 0.11 & 0.11 & 0.13 \\
$\bar{R}^{2}$ & 0.95 & 0.96 & 0.97 & 0.97 & 0.97 & 0.97 \\
$S E E$ & 0.41 & 0.36 & 0.34 & 0.33 & 0.35 & 0.34 \\
\hline \hline & & & & & &
\end{tabular}

Notes: The regressions shown are estimates of the equation:

$$
f_{t}=\rho f_{t-1}+(1-\rho)\left(a_{o}+a_{\pi} \pi_{t+i}+a_{y} y_{t+i}\right)
$$

The columns correspond to different values for $i$. In the top panel $\rho$ is restricted to zero. The standard errors shown under the parameter estimates are based on the Newey-West heteroskedastity and serial correlation robust estimator. 
Table 9

\section{Forward Looking Rules Estimated with 1994:4 Data}

\section{Estimation}

\begin{tabular}{lrrrrrr}
\hline \hline & \multicolumn{6}{c}{ Horizon Relative to Decision Period (in Quarters) } \\
\cline { 2 - 7 } & \multicolumn{1}{c}{0} & \multicolumn{1}{c}{1} & \multicolumn{1}{c}{2} & \multicolumn{1}{c}{3} & \multicolumn{1}{c}{4} \\
\hline \hline$a_{0}$ & 4.36 & 1.13 & -0.74 & -1.62 & -2.21 & -1.89 \\
& 1.18 & 1.16 & 0.95 & 0.82 & 0.72 & 0.54 \\
$a_{\pi}$ & 0.70 & 1.54 & 2.04 & 2.28 & 2.45 & 2.37 \\
& 0.28 & 0.28 & 0.23 & 0.21 & 0.20 & 0.17 \\
$a_{y}$ & 0.88 & 0.60 & 0.33 & 0.09 & -0.15 & -0.34 \\
& 0.07 & 0.06 & 0.08 & 0.10 & 0.12 & 0.12 \\
$\bar{R}^{2}$ & 0.93 & 0.93 & 0.89 & 0.84 & 0.80 & 0.78 \\
$S E E$ & 0.52 & 0.51 & 0.64 & 0.76 & 0.85 & 0.91 \\
\hline$a_{0}$ & 8.24 & 3.55 & 1.14 & -1.62 & -3.57 & -7.41 \\
& 3.56 & 2.28 & 1.50 & 1.05 & 1.47 & 12.24 \\
$a_{\pi}$ & -0.39 & 0.86 & 1.49 & 2.24 & 2.75 & 3.72 \\
& 0.99 & 0.61 & 0.38 & 0.26 & 0.37 & 3.01 \\
$a_{y}$ & 1.47 & 1.16 & 1.05 & 0.71 & 0.61 & 2.96 \\
& 0.50 & 0.39 & 0.34 & 0.36 & 0.61 & 8.50 \\
$\rho$ & 0.69 & 0.67 & 0.73 & 0.74 & 0.81 & 0.95 \\
& 0.18 & 0.15 & 0.08 & 0.10 & 0.11 & 0.13 \\
$\bar{R}^{2}$ & 0.96 & 0.97 & 0.96 & 0.96 & 0.96 & 0.95 \\
$S E E$ & 0.37 & 0.32 & 0.37 & 0.39 & 0.39 & 0.42 \\
\hline \hline
\end{tabular}

Notes: The regressions shown are estimates of the equation:

$$
f_{t}=\rho f_{t-1}+(1-\rho)\left(a_{o}+a_{\pi} \pi_{t+i}+a_{y} y_{t+i}\right)
$$

The columns correspond to different values for $i$. In the top panel $\rho$ is restricted to zero. The standard errors shown under the parameter estimates are based on the Newey-West heteroskedastity and serial correlation robust estimator. 
Figure 1

\section{Taylor's Rule}

Based on Detrended Output Potential

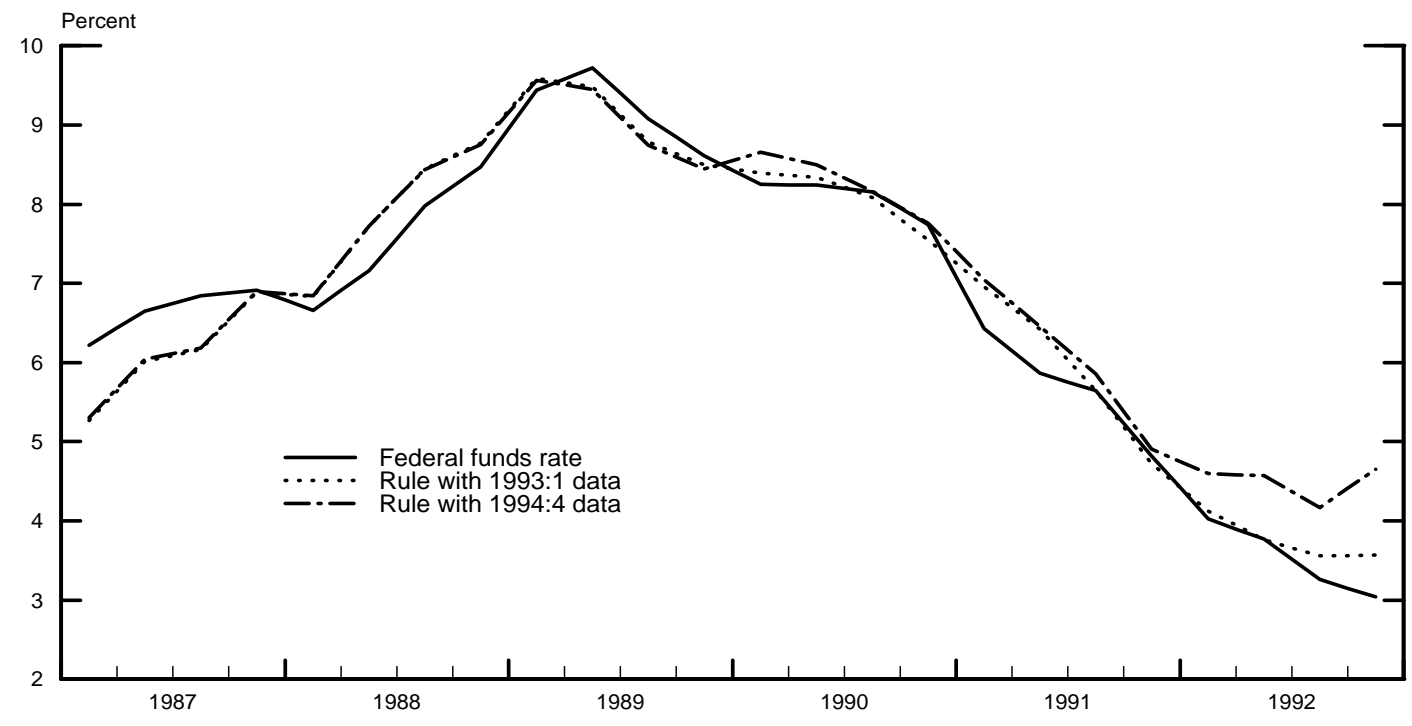

Based on $Q^{*}$

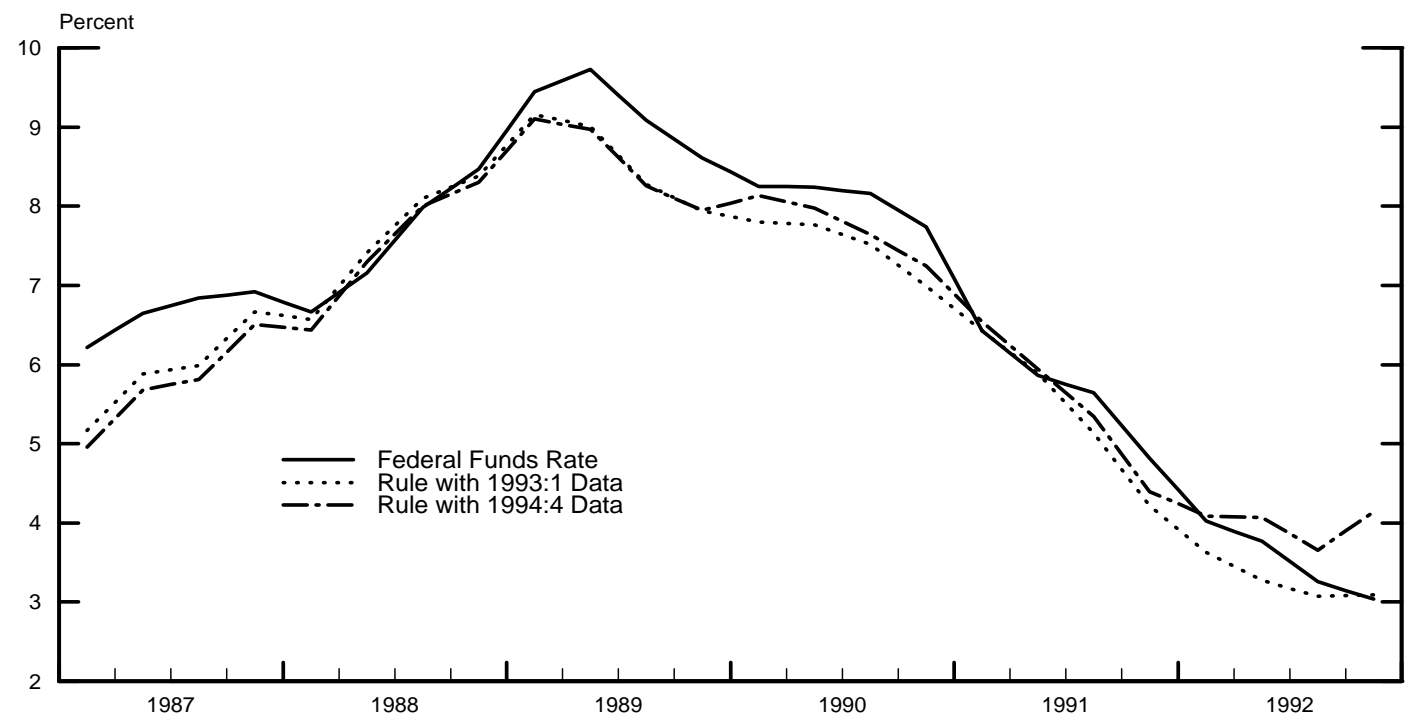


Figure 2

\section{Taylor's Rule Based on Real-Time and Revised Data}

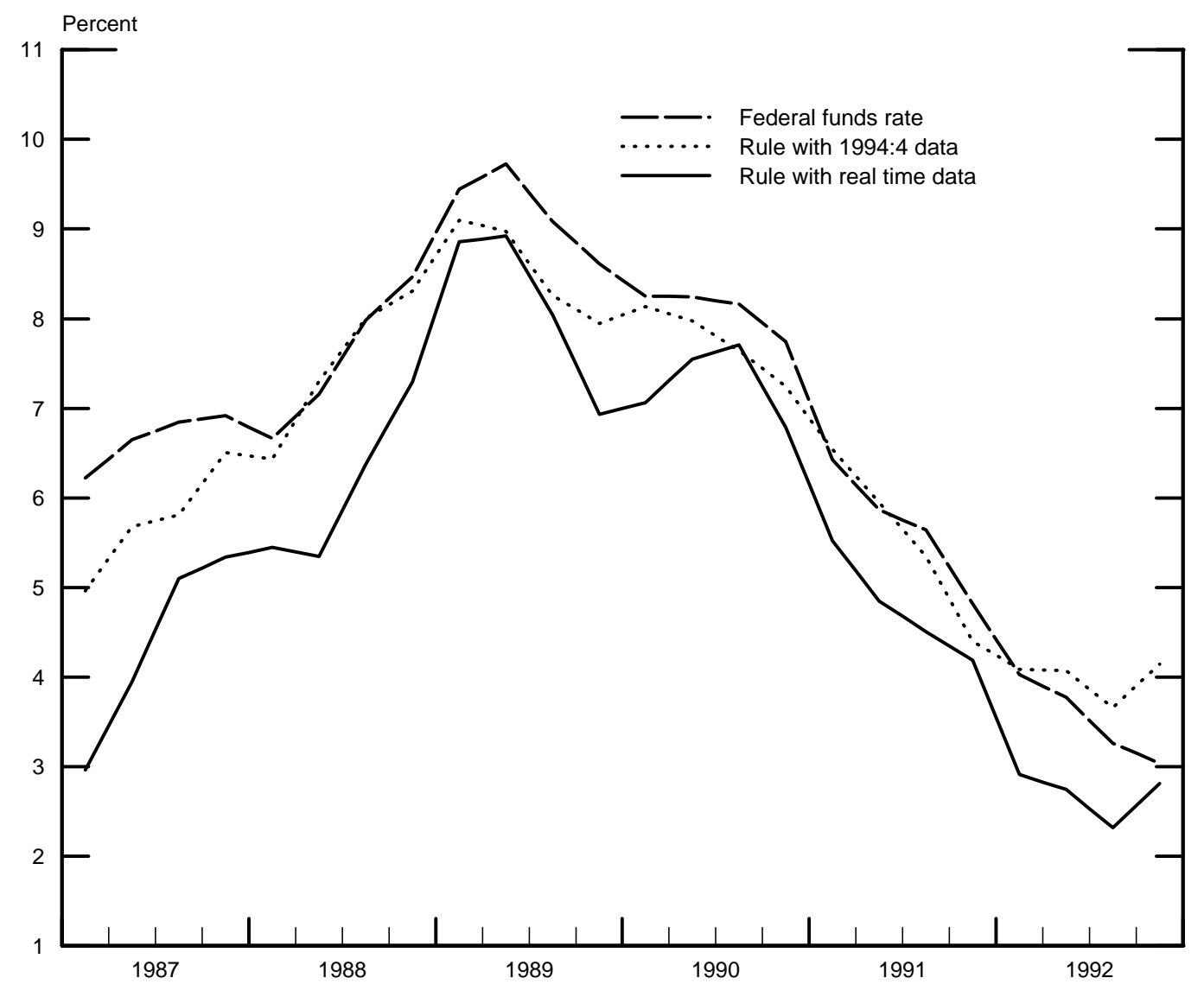

Note: For each quarter, the solid line indicates the level of the federal funds rate recommended by the rule based on output and inflation estimates available in real time. The dotted line shows the ex-post recommendations using data as of 1994:4. Both rules are based on the $Q^{*}$ concept of potential output. 
Figure 3

\section{Underlying Real-Time and Revised Data}

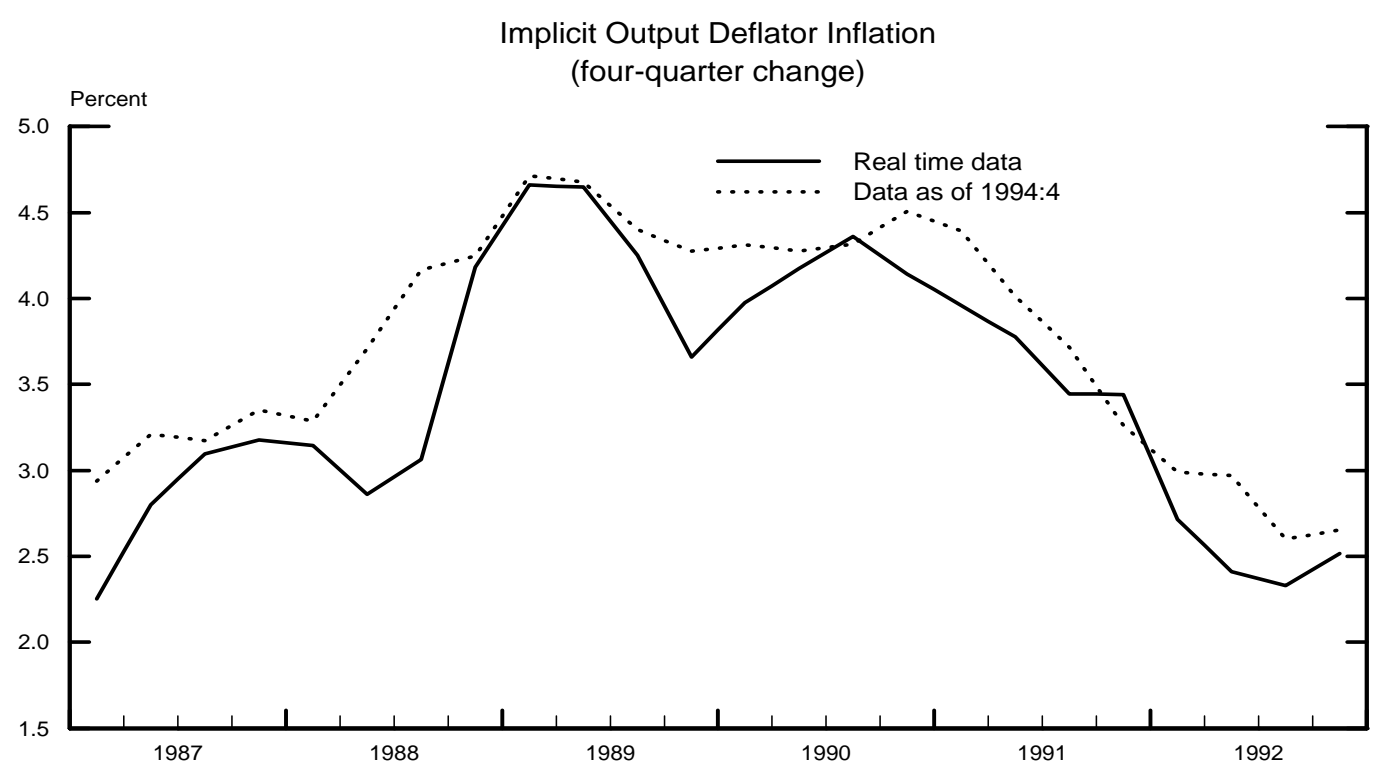

Output Gap

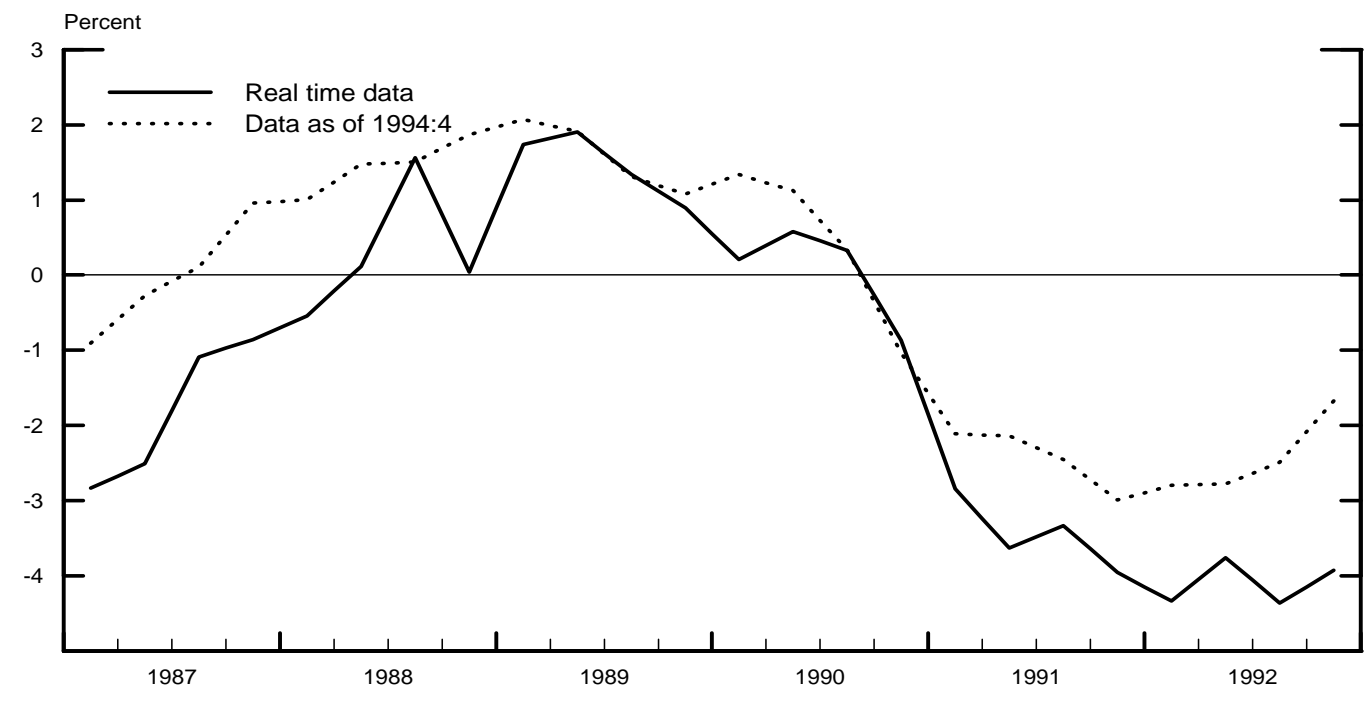


Figure 4

\section{Real-Time Rule and Revisions Within a Year}

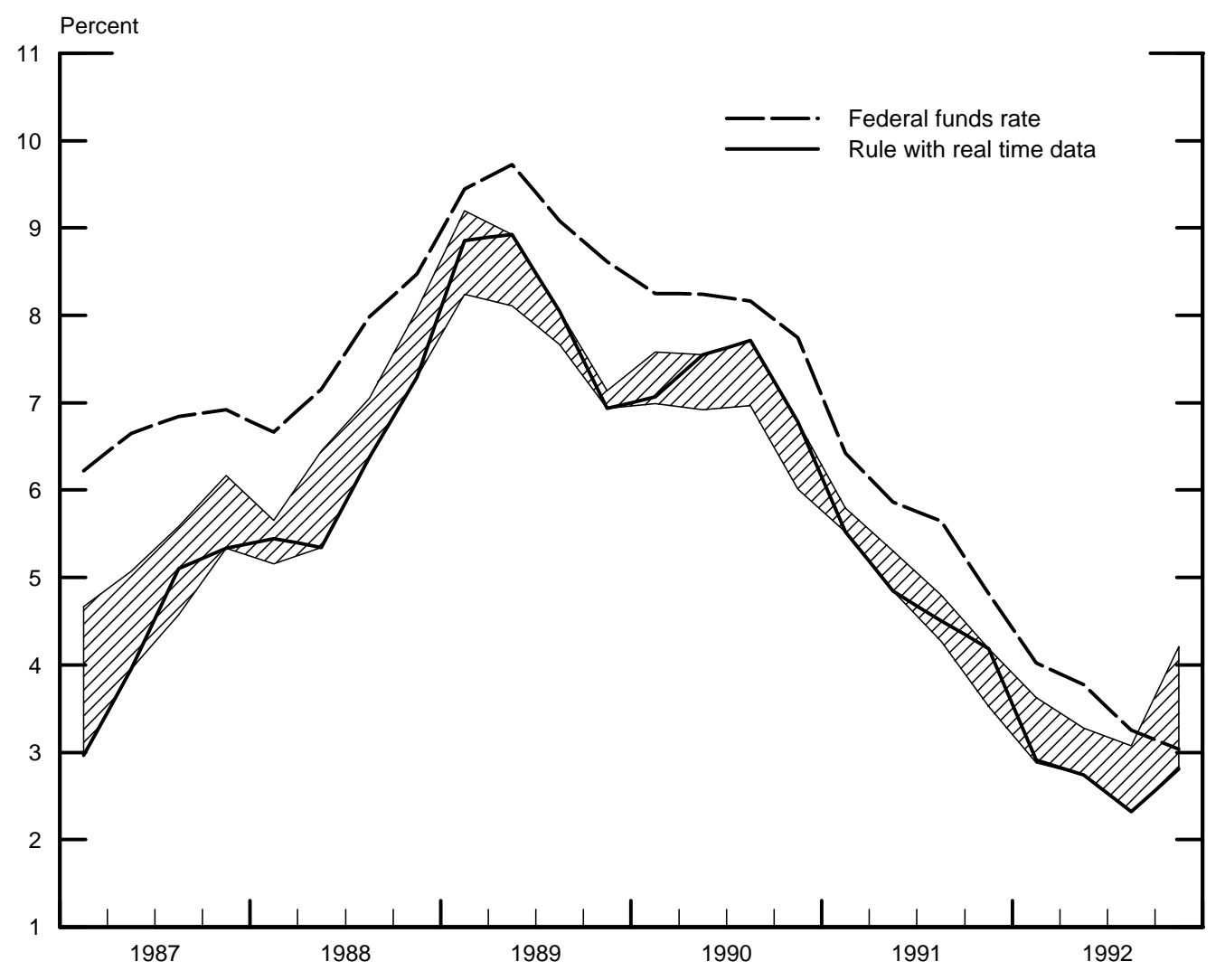

Note: For each quarter, the envelope around the rule indicates the range of recommendations for the federal funds rate that would obtain using data as of that quarter and as of each of the subsequent four quarters. 
Figure 5

\section{Decomposition of Within-Year Revisions}
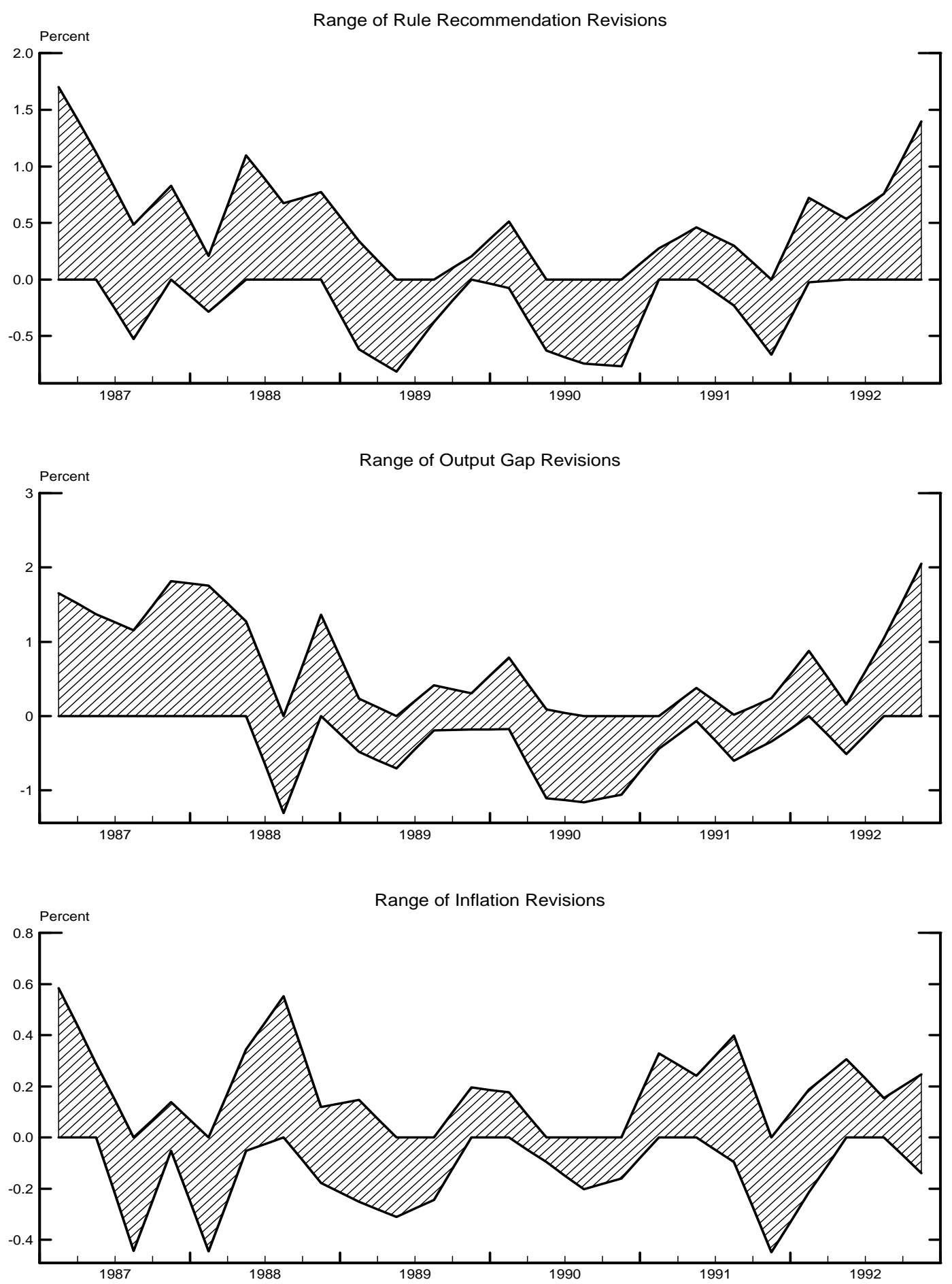